\title{
Late components of motor unit potentials in central core disease
}

\author{
J. M L L P EZ-TERRADAS A N D . CONDE LOPEZ \\ From the Ciudad Sanitaria de la Seguridad Social "La Paz", Department of Pediatrics, \\ Service of Neurology, Madrid, Spain
}

SUMMARY Electromyographic studies in five patients suffering from central core disease are presented. A variable amount of late components of motor unit potentials were found in all of them, as others have found in Duchenne muscular dystrophy. This suggests the existence of collateral innervation of the resultant fragments of the muscular fibre splitting present in this disorder.

Since the original description in 1956 by Shy and Magee of central core disease as a nonprogressive myopathy, several ideas have been suggested on the nature of the disease. The histochemical similarity between target fibres and central cores led Engel (1967) to postulate a neurogenic factor in the genesis of central core disease. The finding of an increased terminal innervation ratio in this myopathy could also be considered to indicate a neural aetiology (Telerman-Toppet et al., 1973; Isaacs et al., 1975).

Longitudinal splitting of muscle fibres in this disease, mainly in type 2 fibres (Telerman-Toppet et al., 1973) with slow replacement with type 1 suggests that the disease is not progressive.

In this report we describe late components of motor unit potentials in central core disease and attempts to correlate them with the morphological changes.

\section{Methods}

Motor unit potentials were recorded from the biceps brachialis and extensor digitorum communis muscles of five patients from two families suffering from central core disease, with an age range of 13 to 43 years. Three of these patients have been reported previously (Pascual Castroviejo et al., 1974). We used a three channel DISA electromyograph and concentric needle electrodes for the recording, according to the usual technique.

Address for reprint requests: Dr José María Lopez-Terradas Covisa, Clinica Infantil "La Paz", Servicio de Neuropediatria, Avda Generalisimo 177, Madrid, Spain.

Accepted 15 November 1978
Twenty motor unit potentials were recorded from each muscle.

Special emphasis was applied to the recording and analysis of the morphology of the motor unit potentials, defined as those which maintain all the components invariable in 10 or more consecutive discharges. A late component of a motor unit potential was considered to be one which was separated by at least $10 \mathrm{~ms}$ from the start of the potential. The number of motor unit potentials presenting one or more late components was expressed as a percentage of the total number of potentials obtained for each muscle and case (see Table).

Table Percentage of late components of motor unit potentials with reference to the total number of potentials obtained for each muscle and case

\begin{tabular}{lllll}
\hline Case & $\begin{array}{l}\text { Age } \\
(y r)\end{array}$ & Sex & $\begin{array}{l}\text { LCBB } \\
(\%)\end{array}$ & $\begin{array}{l}\text { LCEDC } \\
(\%)\end{array}$ \\
\hline 1 & 14 & M & 16 & 12 \\
2 & 17 & F & 12 & 7 \\
3 & 24 & F & 21 & 20 \\
4 & 13 & M & 15 & 7 \\
5 & 43 & M & 21 & 14 \\
\hline
\end{tabular}

$M=$ male; $F=$ female; $\mathbf{L C B B}=$ late components, biceps brachialis muscle; $\mathrm{LCEDC}=$ late components, extensor digitorum communis muscle.

\section{Case reports}

\section{FAMILY 1}

Case 1 A 14 year old boy (MMR) started walking at the age of 14 months. He runs or goes upstairs with some difficulty, but without any help. Clinical 
examination disclosed mild bilateral paresis and atrophy of the deltoid muscle. Reflexes were diminished and the Gowers' manoeuvre was positive. There was bilateral pes cavus.

Case 2 A 17 year old girl (EMR) started walking at the age of 13 months. She manages to walk correctly, but she cannot jump or run. Clinical examination showed muscles with marked fatty infiltration. Mild paresis was mainly proximal. Standing up from the lying position was difficult. Gowers' manoeuvre was positive. Tendon reflexes were diminished. There was bilateral pes cavus.

Case 3 A 24 year old woman (JMR) started walking at the age of 19 months with clumsy gait. She now walks well, but needs some help to go upstairs. Clinical examination revealed mild paresis predominantly in the proximal muscles, and difficulty of dorsiflexion of both feet, Gowers' manoeuvre was positive, and the reflexes were markedly diminished. There was bilateral pes cavus.

\section{FAMILY 2}

Case 4 A 13 year old boy (MCM) started walking at the age of 18 months. He walks without any problem, but has some difficulty in running or climbing stairs. He does not need any help. On examination he had mild generalised paresis with diminished tendon jerks and kyphoscoliosis. He wears an orthopaedic corset.

Case 5 A 43 year old man (MCL) was probably late to begin walking. He eventually managed to walk correctly, but since he was very young he has felt weakness soon after exercise. Examination showed mild paresis, mainly proximal, with diminished reflexes, no muscular atrophies, and no diffculty in standing up from the floor.

\section{Results}

\section{HISTOLOGICAL FINDINGS}

The diagnosis was established by histological study. Biopsies of the vastus lateralis muscle were performed in all patients. All samples showed a variation in fibre size. Fibrous and fatty tissues were present in increased amounts. Histochemical study revealed a predominance of type 1 fibres, being almost entirely type 1 in case $5(90 \%)$. The type 1 fibres showed evidence of central areas devoid of oxidative enzymes in a variable percentage from case to case (varying between 15 and $80 \%$ ). Muscle fibre necrosis was sparse.

\section{ELECTROMYOGRAPHY}

Electromyographic investigation disclosed late components appearing more than $10 \mathrm{~ms}$ after the

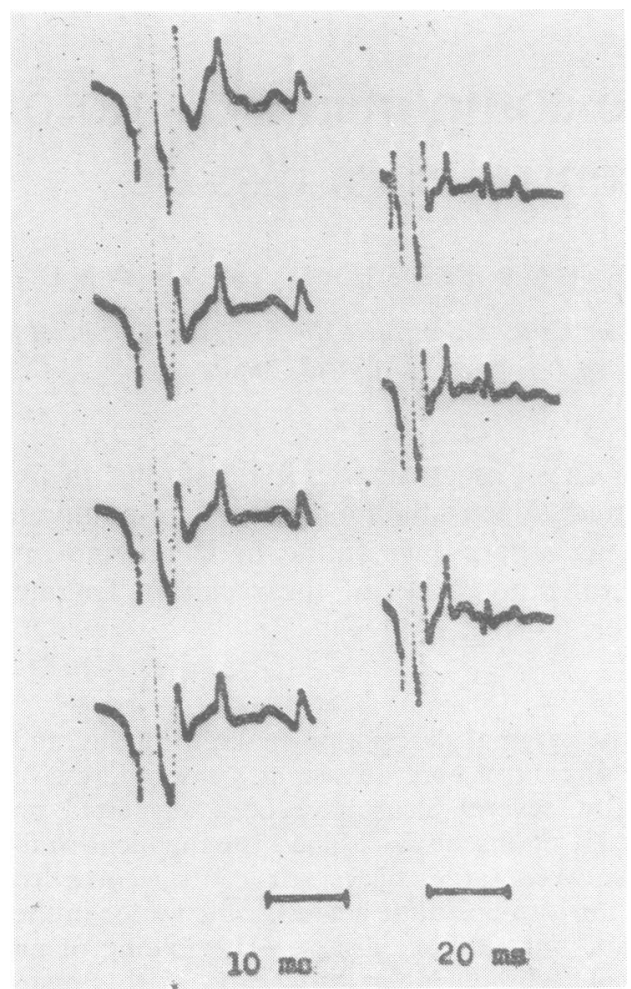

Fig. 1 MCL, 43 yr. Biceps brachialis muscle. A moto unit potential with late components, recorded at different sweep velocities.

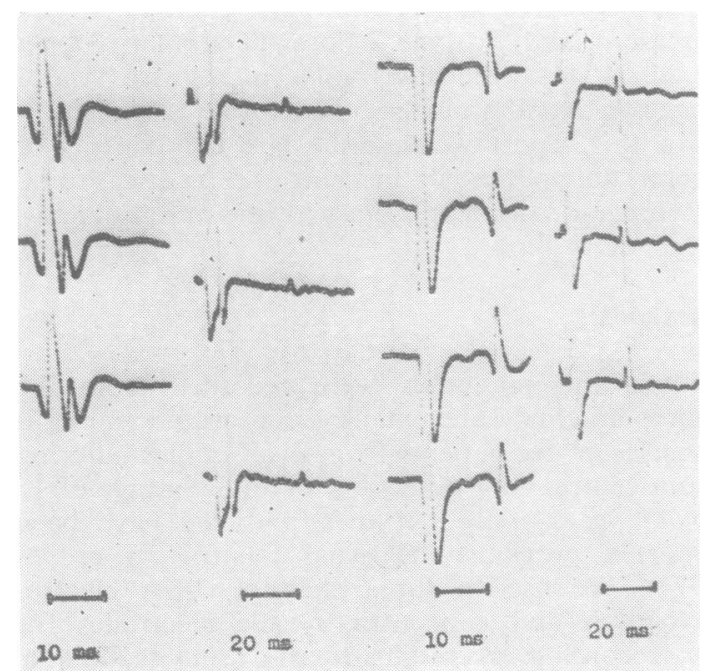

Fig. $2 M C L, 43$ yr. Biceps brachialis muscle. Two motor unit potentials with late components. The late component of the first motor unit potential appeared at a sweep velocity of $20 \mathrm{~ms} /$ division. 


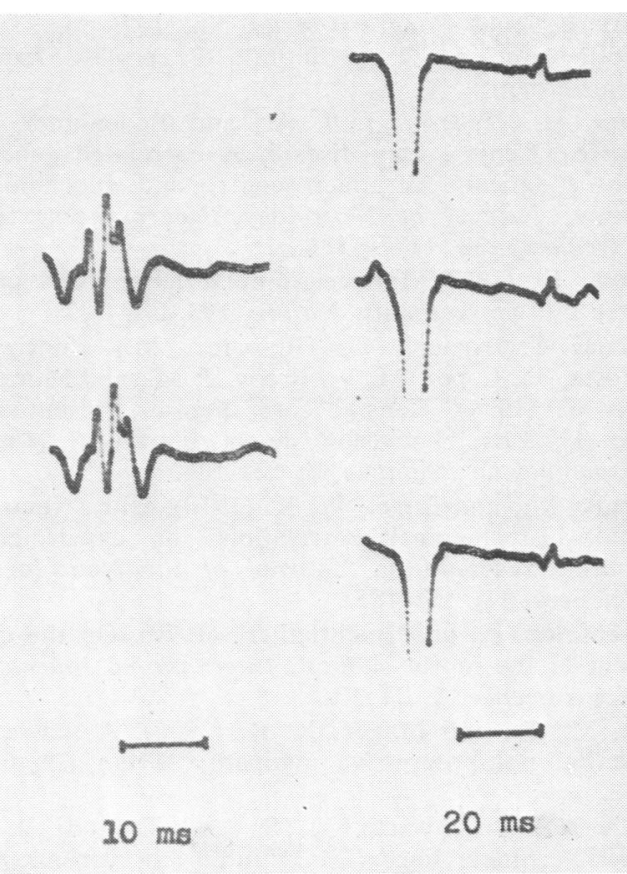

Fig. 3 MCM, 13 yr. Biceps brachialis muscle. Two motor unit potentials, one with late component which appeared at about $38 \mathrm{~ms}$ after the initial action potential.

initial action potential of a motor unit (Figs. 1, 2, 3 ). Their percentage with reference to the total number of potentials obtained (20) is shown in the Table. The greatest percentage of late components was recorded from the biceps muscle with a tendency to increase with age. The interval between the beginning of the potential and the late component varied considerably, the maximum interval being $50 \mathrm{~ms}$.

No late components were found from the recordings of muscle of normal subjects with the same age and sex characteristics but Rosenfalck and Buchthal (1970) indicated that in about $3 \%$ of their recordings from normal muscle, the main motor unit potential was followed by an isolated spike ocurring 9-16 ms later.

\section{Discussion}

In muscular disorders of neurogenic origin, polyphasic motor unit potentials with a great number of late components are frequently observed (Borenstein and Desmedt, 1973; Stalberg et al., 1975). This can be related to the formation of terminal sprouts which, growing from preserved axons, would reinnervate the previously denervated muscular fibres.

Nevertheless, the presence of motor unit potentials with late components is not exclusive to - neurogenic disorders. They may be present also in muscular dystrophies, mainly in the Duchenne type (Desmedt and Borenstein, 1973, 1975, 1976; Stalberg et al., 1974).

This feature can be interpreted in several ways. On the one hand small groups of fibres in regeneration may receive collateral innervation from neighbouring axonal shoots (Reznik and Engel, 1970). On the other hand, a viable fragment of a muscular fibre may become separated from its primitive innervation because of focal necrosis (Denny-Brown, 1960), with later reinnervation (Miledi, 1962). Lastly, longitudinal splitting of the muscle fibres may lead to the formation of viable fragments entirely separated from the original fibre (Dubowitz and Brooke, 1973; Swash and 1 Schwartz, 1977), and then receive innervation from the neighbouring axons, occasionally changing their histochemical type as a response to their new innervation. (Aloisi et al., 1974).

Whatever the mechanism, an increase of the terminal innervation ratio should be expected. However Coërs and Telerman-Toppet (1977) have found a normal terminal innervation ratio in Duchenne type muscular dystrophy. This increases the probability that the reinnervation in this disorder takes place by growth of the nerve endings which become isolated by the necrosis of the muscular fibres innervated by them, and not by formation of collateral sprouts.

In our cases of central core disease, the presence of polyphasic motor unit potentials, with a high percentage of late components suggests the possibility of the existence of collateral reinnervation in this disorder, as has been suggested by other authors who found an increase of the terminal innervation ratio (Telerman-Toppet et al., 1973; Isaacs et al., 1975; Coërs et al., 1976).

As muscle fibre necrosis is scanty in central core disease, the free terminal axons are also very limited in number. The collateral reinnervation would, therefore, be provided by the formation of new terminal sprouts.

Muscle fibre splitting has also been described in central core disease (Telerman-Toppet et al., 1973). This finding, with the increased terminal innervation ratio, strongly suggests the existence of collateral reinnervation of the resulting fragments of the splitting and satisfactorily explains the finding of late components in the EMG. 


\section{References}

Aloisi, M. Dierobon Bormioli, S., and Schiaffino, S. (1974). Cell multiplication and histochemical changes in compensatory muscle hypertrophy. In Structure and Function of Normal and Diseased Muscle and Peripheral Nerve, pp. 27-32. Edited by I. Hausmanowa-Petrusewicz and $\mathrm{H}$. Jedrezejowska. Polish Medical Publishers: Warsaw.

Borenstein, S., and Desmedt, J. M. (1973). Electromyographical signs of collateral reinnervation. In New Developments in Electromyography and Clinical Neurophysiology, vol. 1, pp. 130-140. Edited by J. E. Desmedt. S. Karger: Basel.

Coërs, C., and Telerman-Toppet, N. (1977). Morphological changes of motor units in Duchenne's muscular dystrophy. Archives of Neurology (Chicago), 34, 396-402.

Coërs, C., Telerman-Toppet, N., Gerard, J. M. Szliwowiski, H., Bethlem, J., and Van Wijngharden, G. K. (1976). Changes in motor innervation and histochemical pattern of muscle fibres in some congenital myopathies. Neurology (Minneapolis), 26, 1046-1053.

Denny-Brown, D. (1960). Experimental studies pertaining to hypertrophy, regeneration and degeneration. Research Publications, Association for Research in Nervous and Mental Diseases, 38, 147196.

Desmedt, J. E., and Borenstein, S. (1973). Collateral innervation of muscle fibres by motor axons of dystrophic motor units. Nature, 264, 500-501.

Desmedt, J. E., and Borenstein, S. (1975). Spontaneous fibrillation potentials in human muscular dystrophy: relation to muscle fiber regeneration. Nature, 258, 531-534.

Desmedt, J. E., and Borenstein, S. (1976). Regeneration in Duchenne dystrophy. Archives of Neurology (Chicago), 33, 642-650.

Dubowitz, V., and Brooke, M. H. (1973). Muscle Biopsy, a Modern A pproach. W. B. Saunders: London.

Engel, W. K. (1967). A critique of congenital myopathies and other disorders. In Exploratory Concepts in Muscular Dystrophy and Related Disorders.
International Congress Series No. 147, pp. 27-40. Edited by A. T. Milhorat. Excerpta Medica: Amsterdam.

Isaacs, H., Heffron, J. J. A., and Badenhorst, M. (1975). Central core disease. A correlated genetic, histochemical, ultramicroscopic, and biochemical study. Journal of Neurology, Neurosurgery, and Psychiatry, 38, 1177-1186.

Miledi, R. (1962). Induced innervation of end plate free muscle segments. Nature, 193, 281-282.

Pascual Castroviejo, I., Gutierrez, M., Rodriguez Costa, T., Lopez, M. V., Ricoy, J. M., and Morales, M. C. (1974). Central core disease. Presentación de 4 casos y revisión de la literatura. Anales Españoles de Pediatría, 7, 524-536.

Reznik, M., and Engel, W. K. (1970). Ultrastructural and histochemical correlations of experimental muscle regeneration. Journal of the Neurological Sciences, 11, 167-185.

Rosenfalck, P., and Buchthal, F. (1970). On the concept of the motor subunit. International Journal of Neuroscience, 1, 27-37.

Shy, M. G., and Magee, K. R. (1956). A new congenital non-progressive myopathy. Brain, 79, 610 622.

Stalberg, E., Schwartz, M. S., and Trontelj, J. V. (1975). Single fibre EMG findings in various processes affecting the anterior horn cell. Journal of the Neurological Sciences, 24, 403-415.

Stalberg, E., Trontelj, J. V., and Janko, M. (1974) Single fibre EMG findings in muscular dystrophy In Structure and Function of Normal and Diseased Muscle and Peripheral Nerve, pp. 185-190. Edited by I. Hausmanowa-Petrusewicz and $\mathrm{H}$. Jedrezejowska. Polish Medical Publishers: Warsaw.

Swash, M., and Schwartz, M. S. (1977). Implications of longitudinal-muscle fibre splitting in neurogenic and myopathic disorders. Journal of Neurology, Neurosurgery, and Psychiatry, 40, 1152-1159.

Telerman-Toppet, N., Gerard, J. M., and Coërs, C. (1973). Central core disease. A study of clinically unaffected muscle. Journal of the Neurological Sciences, 19, 207-223. 